\section{Problematização como estratégia de educação nutricional com adolescentes obesos}

\author{
Problem-posing as a nutritional education \\ strategy with obese teenagers
}

\author{
1 Faculdade de Ciências \\ Medicas, Universidade \\ Estadual de Campinas, \\ Campinas, Brasil. \\ Correspondência \\ E. M. Rodrigues \\ Departamento de \\ Enfermagem, Faculdade \\ de Ciências Médicas, \\ Universidade Estadual \\ de Campinas. \\ Rua Madre Cecília 1560, \\ Bloco B 11, Piracicaba, SP \\ 13400-490, Brasil. \\ erikamr@terra.com.br
}

\begin{abstract}
Obesity is a public health issue with relevant social determinants in its etiology and where interventions with teenagers encounter complex biopsychological conditions. This study evaluated intervention in nutritional education through a problem-posing approach with 22 obese teenagers, treated collectively and individually for eight months. Speech acts were collected through the use of word cards, observer recording, and tape-recording. The study adopted a qualitative methodology, and the approach involved content analysis. Problem-posing facilitated changes in eating behavior, triggering reflections on nutritional practices, family circumstances, social stigma, interaction with health professionals, and religion. Teenagers under individual care posed problems more effectively in relation to eating, while those under collective care posed problems in relation to family and psychological issues, with effective qualitative eating changes in both groups. The intervention helped teenagers understand their life history and determinants of eating behaviors, spontaneously implementing eating changes and making them aware of possibilities for maintaining the new practices and autonomously exercising their role as protagonists in their own health care.
\end{abstract}

Nutrition Education; Health Education; Obesity; Adolescent Nutrition
Érika Marafon Rodrigues 1 Maria Cristina Faber Boog 1

O sobrepeso e a obesidade atingem, no Brasil, um percentual de $50 \%$ dos homens e $53,1 \%$ das mulheres, acima de vinte anos, segundo a Pesquisa de Orçamentos Familiares (POF 20022003) 1. Magalhães \& Mendonça 2, utilizando dados de 1996 a 1997, avaliaram a prevalência de sobrepeso e obesidade em adolescentes de 15 a 19 anos nas regiões Norte e Sudeste do Brasil constatando que a mesma foi de $8,45 \%$ no Nordeste e $11,53 \%$ no Sudeste. Estes autores fazem recomendações acerca da prevenção, sugerindo reeducação alimentar e estímulo à atividade física.

Revisando a literatura sobre obesidade na adolescência, observa-se que os trabalhos publicados revelam a existência de estudos abordando dados epidemiológicos, estatísticos, modelos de atendimento em saúde, práticas alimentares dos jovens obesos, assim como seus sentimentos em relação ao problema. Vários deles enfatizam a necessidade de intervenções educativas especificamente voltadas à educação em nutrição, entretanto, quase não há estudos que busquem o aprimoramento das estratégias educativas. Os trabalhos encontrados na literatura que mais se aproximaram desse aspecto foram de Boog 3, Muller 4, Holli \& Calabrese 5 , Motta 6 e Garcia 7 .

Obesidade é um problema de saúde pública em cuja etiologia determinantes sociais têm relevância, sendo que intervenções com adolescentes encontram condição biopsicossocial 
complexa que exige que se trabalhe com abordagens amplas que considerem os determinantes culturais e sociais do problema. A família retrata o ambiente primeiro para socialização e os alimentos são um dos principais símbolos de união dos grupos, configurando a cultura alimentar, na qual a criança é iniciada durante ou após o desmame 8 . Além do ambiente micro social é preciso considerar que a sociedade de consumo é uma sociedade obesogênica na medida em que estimula o consumo alimentar.

A dinâmica familiar assume papel considerável na mudança de práticas alimentares para controle ou tratamento da obesidade, porém, muitas vezes, a família atribui todo o dever de mudança de hábito alimentar aos filhos, negando assim sua parcela de responsabilidade.

A educação nutricional pode promover o desenvolvimento da capacidade de compreender práticas e comportamentos, e os conhecimentos ou as aptidões resultantes desse processo contribuem para a integração do adolescente com o meio social, proporcionando ao indivíduo condições para que possa tomar decisões para resolução de problemas mediante fatos percebidos.

A intervenção selecionada para o presente estudo está baseada no aconselhamento dietético conforme descrito por Holli \& Calabrese 5 , porém, buscou-se enriquecer essa forma de intervenção atrelando a ela a visão de problematização ${ }^{9}$, que consiste na busca ativa pelo educando do desvelamento dos mecanismos de opressão, de forma que ele venha a empreender esforços para lograr melhor condição de vida, emancipação, defesa da existência digna e autonomia. É uma intervenção de educação voltada para a formação de valores, do prazer, da responsabilidade, da criticidade, do lúdico e da liberdade. O modelo de aconselhamento se pauta no reconhecimento da importância de identificar e responder aos aspectos afetivos como também aos comportamentais 10. Dessa forma, o conceito de aconselhamento dietético adotado pelas autoras é o de uma abordagem de educação nutricional, que se efetua pelo diálogo entre o cliente, portador de uma história de vida, que procura ajuda para solucionar problemas de alimentação, e o nutricionista, preparado para analisar o problema alimentar em seu contexto biopsicossociocultural. Cabe ao profissional auxiliar o cliente a explicitar os conflitos que permeiam o problema alimentar, para buscar soluções por meio da criação de estratégias de enfrentamento dos problemas alimentares na vida cotidiana 11 . Além disso, propõe-se ainda, incluir nesse processo a problematização, estimulando o adolescente para uma reflexão crítica, por meio da qual ele possa compreender a influência macro e micro social na instalação e manutenção da obesidade.

É importante considerar que o processo de aconselhamento não busca impor ao cliente respostas prontas para o problema, mas sim estabelecer uma relação de ajuda entre o aconselhador e o cliente, efetivada por meio das etapas do aconselhamento, quais sejam: descoberta inicial, caracterizada pela formação do vínculo; exploração em profundidade, fase na qual deve haver a problematização e discussão dos problemas; e preparação para a ação, momento de formulação de estratégias para o enfrentamento dos problemas alimentares.

Por intermédio da intervenção educativa realizada nesse estudo, procurou-se identificar os problemas emergentes que poderiam levar à descoberta das necessidades de ações educativas que se aproximassem mais das demandas dos adolescentes.

O objetivo do presente estudo é descrever a problematização efetuada pelos adolescentes ao longo da atividade educativa e as mudanças no comportamento alimentar decorrentes desse processo.

\section{Método}

Foram estudados, por um período de oito meses, 22 adolescentes, sendo nove do sexo masculino e 13 do feminino, com idades entre $11 \mathrm{e}$ 16 anos e diagnóstico de obesidade exógena, encaminhados pelo Ambulatório Geral de Adolescência do Hospital das Clínicas da Universidade Estadual de Campinas (UNICAMP) e por uma Unidade Básica de Saúde de Campinas.

Inicialmente todos os adolescentes foram avaliados individualmente em entrevista, na qual foram abordadas questões de comportamento alimentar, aspectos cognitivos relativos à doença, representações sociais, dados quanti-qualitativos referentes à alimentação atual, além de espaço aberto para a manifestação espontânea dos adolescentes. O uso de questões abertas pode extrair respostas com palavras próprias do entrevistado, além de encorajá-lo na ampliação e revelação de suas idéias 12 .

Feita a entrevista com os adolescentes, houve o encaminhamento de 11 para o atendimento individual, no qual utilizou-se fita cassete para registro das falas, e de outros 11 para o atendimento coletivo, onde a pesquisadora contou com o auxílio de uma psicóloga, como observadora, para fazer o registro dos encontros.

Ambas as formas de atendimento consideraram o aconselhamento dietético como su- 
porte para a educação nutricional. A estratégia adotada para o desenvolvimento do programa foi a problematização, a qual rejeita situações formais de ensino-aprendizagem e engloba a construção autônoma de estratégias e ações que se identificam com a realidade e história de vida do sujeito 9,13 .

\section{Atendimento individual}

Foi realizado quinzenalmente, permanecendo cada adolescente, em média, 45 minutos com a pesquisadora, em todos os encontros. $\mathrm{O}$ aconselhamento visou a ajudar os adolescentes a se posicionarem diante do nutricionista, de modo que pudessem desvelar detalhes do seu comportamento alimentar, e levantar estratégias, para que, independentemente, problematizassem e realizassem mudança gradativa das práticas. Nos atendimentos procurou-se acolher as demandas dos adolescentes, as quais emergiram ao longo de 16 encontros.

\section{Atendimento coletivo}

Foi realizado quinzenalmente e cada reunião teve duração de duas horas. Foram empregadas técnicas de dinâmica de grupo 14 para auxiliar os adolescentes a desvelar detalhes do seu comportamento alimentar e compartilhar as descobertas com os demais membros do grupo, para que, coletivamente, pudessem analisar seus comportamentos e buscar estratégias para a mudança gradativa de práticas. O planejamento foi formulado com base nas demandas do próprio grupo, não tendo sido elaborado, portanto, o cronograma de atividades. O programa constou igualmente de 16 encontros. As dinâmicas de grupo contribuíram para promover a integração grupal, estimular o autoconhecimento, desenvolver o senso crítico com relação à mídia e à sociedade, aproximar os adolescentes do universo alimentar, possibilitar a interação e a auto-avaliação.

Para a análise dos registros das falas foi empregado o método qualitativo, o qual permite conhecer e compreender o sentido e o significado dos fenômenos no cotidiano ${ }^{15}$. A análise hermenêutica contribui para a compreensão das falas, dos depoimentos e do processo de construção de conhecimento e, articulada à abordagem dialética possibilita alcançar uma interpretação mais aproximada da realidade tal qual vivenciada pelos sujeitos em seu meio social, econômico e cultural 12 .

O projeto foi aprovado pelo Comitê de Ética em Pesquisa da Faculdade de Ciências Médicas da UNICAMP no parecer 119/2001.

\section{Resultados}

As respostas dos adolescentes foram reunidas em categorias referentes aos temas problematizados nos atendimentos coletivo e individual, quais sejam: práticas alimentares, relacionamento familiar, estigma social do obeso, relação com profissionais de saúde e religião, categoria esta surgida apenas no atendimento coletivo. Para a preservação da identidade dos adolescentes foram utilizados nomes fictícios. Após o nome, foi colocada a idade seguida pela letra $\mathrm{C}$ para atendimento coletivo e a letra I para o atendimento individual.

\section{Práticas alimentares - possibilidades} reduzidas a comer certo versus comer errado

A utilização dos alimentos está representada e reduzida para os adolescentes a duas possibilidades: comer certo e comer errado. O comer certo está associado aos alimentos por eles considerados bons e, o comer errado, aos maus. Alguns dos alimentos bons, citados pelos adolescentes, foram: frutas e sucos de frutas, hortaliças, arroz, feijão, carnes, e os maus: pães, massas, maionese, refrigerantes, doces em geral. Esse pensamento dicotômico impede que os adolescentes, e também seus familiares, procedam a um balanceamento, busquem o equilíbrio, pois o comer certo pressupõe a exclusão de todos aqueles que compõem o grupo dos maus.

Do comer errado, fazem parte, ainda, a ingestão hídrica às refeições cuja conseqüência foi explicitada dizendo que "a comida vira lavagem no estômago” (Pedro, 13 anos, I), e algumas combinações de alimentos: o consumo de maionese no pão é considerado "errado" e o de margarina "certo", embora o valor calórico da maionese seja equivalente ao da margarina.

Na percepção dos adolescentes, o comer certo deve ser seguido de atividade física imediata, que então é realizada sem nenhum prazer, com o objetivo de queimar as calorias advindas dos alimentos previamente consumidos. O comer certo torna-se um ideal inatingível porque é percebido como restrição e anulação do prazer, implicando portanto, a exclusão sumária de um grande número de alimentos que fazem parte da cultura alimentar e da vida social.

Essas representações culturais são reforçadas pela autoridade de profissionais de saúde que, desconhecendo outras formas de abordar o problema, repetem o que tradicionalmente lhes foi transmitido, que é a noção de um comer certo e um comer errado. A problematização consiste na ruptura desse padrão dicotômico de pensamento, de forma que o adoles- 
cente passe a perceber que não existem apenas duas formas de alimentar-se. A curiosidade natural dos jovens e o vínculo com o profissional são condições para que ele passe a problematizar as questões do cotidiano, buscando desenvolver estratégias próprias de enfrentamento. Em alguns casos, a estratégia de enfrentamento é a própria percepção dos mecanismos de manipulação do comportamento alimentar empregados pela propaganda, pois ao tomarem consciência da maneira como são manipulados, elaboram uma crítica a esse sistema econômico que os mantêm presos a uma rede consumista.

"Ah, eu tô assim na TV e no filme [de uma emissora de TV] fala 'agora sente no seu sofá, abra [um refrigerante] e acompanhe o filme'. Você precisa abrir [um refrigerante] pra assistir o filme? Eles fazem com a gente que nem fantoche" (José, 13 anos, I).

"A gente se sente um mosquitinho preso na teia da aranha” (Andréia, 11 anos, C).

"A propaganda põe gente bonita, magrinha, fazendo acreditar que é isso" (Pedro, 13 anos, I).

\section{Contexto familiar - a rede de apoio que também representa o desamparo}

A dependência afetiva familiar foi uma condição manifestada ao longo do programa, especialmente pelos adolescentes em atendimento coletivo, e sentimentos de angústia e ansiedade foram relacionados à ausência do dialogo, juntamente com o desinteresse dos familiares em discutir mais profundamente os aspectos relacionados à alimentação. A obesidade é vista como um problema a ser resolvido sem a participação dos outros membros da família, os quais mantêm um distanciamento, depositando a responsabilidade das mudanças de comportamento apenas nos jovens obesos. Entretanto, quando a família participa, o faz de forma autoritária, racionalista e pragmática sem incorporar outros fatores causais da obesidade, o que reforça o consumo alimentar inadequado. O diálogo limitado acarreta dificuldades emocionais, impede a problematização e a atitude reflexiva. A omissão da família em relação às mudanças de comportamento coloca o adolescente obeso em confronto com conhecimentos e práticas divergentes, o que acirra conflitos familiares.

"Quanto mais falam pra eu emagrecer, daí eu como mais, meu pai falava 'tem que emagrecer', aquilo dava um desespero, eu comia mais" (Maria, 13 anos, I).

"Meu pai fica vendo televisão. Talvez tenha medo de falar um com o outro. É difícil explicar.
Tenho medo que cortem as coisas que eu gosto" (Tiago, 14 anos, I).

\section{Estigma social - a busca por uma} identidade em meio à discriminação

O estigma e a discriminação, sentimentos exteriorizados pelos adolescentes em ambos os atendimentos, demarcaram obstáculos para efetivar mudanças no comportamento alimentar. Os sentimentos de frustração e medo, conseqüentes do estigma de "ser gordo(a)", podem impedir que os adolescentes problematizem as práticas cotidianas, e acabem aquiescendo às dietas rígidas como estratégias imediatas, supostamente úteis para o tratamento da obesidade.

O estigma da obesidade carregado de intensa carga psicológica procede do grupo social e da família, abalando a estrutura psíquica dos adolescentes. Quando dizem "meu pai me chama de baleia" (Claudia, 11 anos, C), a baixa auto-estima pode surgir em decorrência dessa exclusão social, gerando crises, tensões, ansiedade, sentimentos que configuram um esquema cíclico comer - angustiar-se - comer, contribuindo, assim, para a manutenção da obesidade.

"Meu irmão me chama de baleia, dizia que eu nunca ia emagrecer, que eu ia ficar gorda pra sempre. Aí eu ficava triste e comia" (Ana, 11 anos, C).

\section{Relação com profissionais de saúde - impressões e expressões dos adolescentes}

O desejo por um tratamento, por meio de dietas padronizadas ou medicamentos, que isente o cliente da responsabilidade de tomar decisões, ocorre normalmente em atendimentos que não privilegiam a história do adolescente e, possivelmente, esses comportamentos são reforçados pela própria forma de tratar a obesidade, pois o cliente deseja "emagrecer do jeito mais fácil" (Pedro, 13 anos, I). A indicação de dietas padronizadas, listas de alimentos proibidos e permitidos, conduz o adolescente a um comportamento submisso durante o desenvolvimento de estratégias de estímulo ao autocontrole alimentar. O medo de não ser compreendido pode fazer com que o jovem não expresse seu pensamento de forma autêntica. A cultura alimentar do adolescente confronta-se com o modelo alimentar sistemático do profissional, acarretando dissociações que conformam uma postura heterônoma do adolescente, o qual passa a necessitar da permissão profissional para o consumo alimentar. Como a for- 
mação da maioria dos profissionais não condiz com práticas educativas problematizadoras, há uma valorização da "obediência" do adolescente às recomendações dietéticas, em detrimento do estímulo à autonomia na tomada de decisões sobre alimentação no cotidiano, impedindo-o de tornar-se sujeito ativo no cuidado à saúde.

"Às vezes uma conversa é melhor do que algo escrito no papel. Se a gente tá pensando no assunto, pode mudar" (Claudia, 11 anos, C).

\section{Religiosidade - fortalecimento de vínculos afetivos ou desvinculação com a problematização?}

A relação existente entre o adolescente obeso e o alimento é cercada de sentimento de privação. Os alimentos têm conotações religiosas e por isso, o comer excessivamente é, muitas vezes, percebido como um ato pecaminoso. $\mathrm{O}$ padrão alimentar hiperfágico e o "comer errado", sempre prazerosos, são marcados pelo sentimento de culpa, seguido de uma autopunição concretizada por meio da privação de alimentos desejados, manifestada como "jejum por penitência” (Andréia, 11 anos, família católica, C). Nos eventos religiosos, como a quaresma, o adolescente justifica a privação auto-imposta como manifestação de sua fé, e consegue, com menor grau de sofrimento, abster-se de certos alimentos, por fazê-lo em função da purificação, quando o sentido atribuído à restrição alimentar amplia-se, tornando-se instrumento de absolvição e de desenvolvimento espiritual. A manifestação religiosa de abstinência praticada em conjunto, com parentes próximos, resgata os vínculos familiares e o adolescente sente-se momentaneamente mais acolhido, o que possibilitou, nesse período, uma redução de peso mais acentuada. No entanto, a religião também pode, ao invés de promover mudanças de comportamento, configurar-se como conformismo, quando torna o problema externo ao adolescente. Ela influencia, portanto, de duas formas: uma em que descompromete o adolescente com a mudança e com o enfrentamento dos problemas alimentares, e outra, na qual ele se envolve em uma abstenção temporária de alguns alimentos, movido por costumes religiosos, vivenciados conjuntamente com familiares e amigos.

"Dizem pra eu não ficar nervoso por ser gordo, que Deus me fez assim" (Pedro, 13 anos, família evangélica, C).

"Na quaresma eu fiquei sem comer chocolate e refrigerante e emagreci" (Maria, 13 anos, família católica, C).

\section{Mudanças efetivadas mediante} o processo de problematização

Foram observadas mudanças nas práticas alimentares e nos aspectos subjetivos do comportamento alimentar, sendo as primeiras mais freqüentes no grupo atendido individualmente e as segundas no atendimento coletivo.

A valorização da produção caseira em detrimento do consumo de alguns produtos industrializados permitiu maior exploração da qualidade nutricional da alimentação dos adolescentes.

"Quando eu vou tomar refrigerante ou sucosuco de saquinho, eu penso que tem pé de limão em casa, aí eu vou lá e faço com limão de casa, e também é mais barato" (Márcia, 13 anos, I).

Os adolescentes apontaram sensações corporais associadas às práticas alimentares, além de manifestarem à família, com mais espontaneidade, suas predileções alimentares.

"Se eu não almoço eu fico com dor de cabeça" (Rosana, 13 anos, I).

"O café da manhã me fez comer pouco no almoço" (Andréia, 11 anos, C).

"Eu chego da escola e almoço, e parece que dá mais força para a tarde" (Maria, 13 anos, C).

"Agora eu não volto mais cansada da escola" (Ana, 11 anos, C) [a adolescente refere-se à reintrodução do café da manhã em seu comportamento alimentar].

"Eu diminui o que eu como, o que eu tomo. $E u$ achava que tinha que ficar sem comer $e$ quando eu comia, eu comia muito. Hoje, eu como cada hora um pouco" (Rosana, 13 anos, I).

"Comer legumes... eu acho isso uma coisa básica. Era assim, todo dia tinha, mas eu não comia. Agora, o meu pai compra mais os legumes que eu gosto" (Viviane, 12 anos, I).

Foram observadas também mudanças nos aspectos psicológicos, como auto-estima e interação social.

“Antes, só a minha opinião prevalecia. Hoje, procuro ouvir a opinião dos outros" (Andréia, 11 anos, C).

"Fui aprendendo com os outros, às vezes, o problema dos outros pode ser maior do que o nosso. Eu acho que estou menos fechada, menos agressiva. Porque quando eu me via no espelho não gostava de mim e descontava nos outros. Agora eu estou gostando mais de mim" (Maria, 13 anos, $\mathrm{C})$.

"Me abri mais, foi muito bom, eu era muito tímida" (Claudia, 11 anos, C).

"Eu me sinto segura, é o fato de eu estar me sentindo melhor" (Carol, 11 anos, I).

Com relação ao peso corporal, $40 \%$ dos adolescentes atendidos em grupo e $66,6 \%$ dos aten- 
didos individualmente apresentaram redução de peso. Entretanto, não foram realizadas avaliações considerando todas as mudanças biológicas ocorridas ao longo dos oito meses, tempo suficiente para alterações próprias dessa fase, por tratar-se de uma pesquisa em educação e não clínica, e assim priorizou-se as mudanças comportamentais.

As mudanças de comportamento, portanto, são realizadas quando o adolescente percebe o sentido dessas em sua história de vida, que engloba o individual e o social, emoção e ação, compreensão dos fatos e segurança para manifestação e enfrentamento dos problemas.

\section{Discussão}

A problematização, temática que balizou este estudo, é uma tarefa complexa aos adolescentes, demandando a necessidade de pensar, de refletir questões que, até então, eles consideravam atribuições exclusivas do profissional, pois as suas condutas seriam aquelas determinadas pelos membros da equipe de saúde.

A estratégia empregada fez emergir cinco temas relevantes ao contexto do comportamento alimentar: a prática alimentar pensada de forma dicotomizada - comer certo versus comer errado; a família como fonte de apoio, mas também de desamparo; as contradições na relação com os profissionais de saúde; o estigma da obesidade; e a religiosidade. É importante ressaltar que o movimento grupal possibilita o emprego de temas transversais que podem ficar ausentes em atendimentos individuais, daí a necessidade de os profissionais estarem habilitados e envolvidos com essas questões para discuti-las, também, no âmbito reservado da consulta individual.

Sobre as questões familiares, vários autores já se detiveram e este estudo confirma as opiniões já apresentadas na literatura. A família pode causar ansiedade no adolescente quando se mostra excessivamente rigorosa em relação à mudança de comportamento alimentar, ou quando se revela resistente ao diálogo. Os adolescentes, especialmente do atendimento coletivo, queixaram-se da ausência de diálogo na família. A existência de conflitos familiares provavelmente acarreta prejuízos na relação que o adolescente tem com o alimento. Essa opinião é reforçada por autores que atribuem distúrbios alimentares a problemas na relação mãe-filho 16,17 .

As várias falas referentes ao núcleo familiar revelaram a importância do desenvolvimento de um trabalho de educação em saúde que con- temple o adolescente junto à família, em um processo extenso, pois a dinâmica familiar é um dos pilares para o comportamento alimentar do adolescente 18, e o padrão alimentar é formado, inicialmente, na família elementar 8 .

A dicotomia comer certo versus comer errado tem raízes na cultura e em experiências pregressas nos próprios serviços de saúde. O despreparo da maioria dos profissionais de saúde para lidar com as questões de alimentação leva à adoção de orientações simplistas, e ao mesmo tempo pouco práticas, porque se preconiza a exclusão de muitos alimentos. As mudanças de comportamento alimentar devem ser conseqüências de um processo reflexivo, por meio do qual o jovem conhece e explora o problema, sem esperar uma mera transmissão de informação sobre o que fazer ${ }^{9}$. A problematização que os adolescentes fizeram a respeito de suas práticas alimentares - entre elas, as dietas restritivas realizadas anteriormente, possibilitoulhes a ampliação da compreensão dos fatos interligados ao comportamento alimentar.

Observou-se que os adolescentes sentiramse negligenciados pelos profissionais de saúde em alguns tratamentos anteriores. Esse descuido esteve relacionado ao tempo exíguo para o diálogo, especialmente para a escuta de suas dificuldades e inquietações, assim como a imposição de tratamentos dietéticos rígidos e inflexíveis. A falta de vínculo profissional-cliente contribui para essa falha na atenção à saúde, configurando uma relação distante entre um cliente dependente e submisso que não reivindica suas necessidades reais de tratamento, e um profissional que pensa isoladamente sua ação. Freqüentemente, esquece-se de que proporcionar saúde é criar meios para ampliar a capacidade de autonomia e padrão de bem-estar 19, condições que ultrapassam os aspectos orgânico-biológicos no cuidado ao adolescente 20 .

As ciências apresentam-se ainda fragmentadas e, assim, cada problema de saúde é tratado isoladamente, o que demanda uma religação entre as várias áreas para a compreensão da complexidade humana 21. Embora haja estudos sobre obesidade balizados pela epidemiologia $22,23,24,25,26$, pela clínica 27 , pela psico$\operatorname{logia} 28$, pela psicologia social 29 , assim como estudos sobre educação nutricional 30 , observa-se a ausência da totalidade no momento das intervenções. O enfoque nos aspectos subjetivos do comportamento alimentar e nas estratégias para a sua compreensão precisa estar associado a fim de se proporcionar a atenção global exigida no tratamento do adolescente obeso. Os resultados confirmaram que o comer está profundamente ligado à cultura, à história 
de vida, ao discurso publicitário, fatos que sustentam a necessidade de novos paradigmas no tratamento de adolescentes obesos.

A obesidade é considerada, por alguns adolescentes, um problema insolúvel, por sentirem-se pressionados e obrigados a realizar determinadas práticas impostas e de difícil concreção. É sabido o impacto que a obesidade acarreta ao adolescente, uma vez que esse está marcado por sofrimento, pela imagem corporal indesejada e por problemas psicossociais, e nesse contexto aparece o estigma como mais um elemento envolvendo a vida cotidiana dos jovens obesos, fato bem evidenciado em ambos os grupos deste estudo.

Ser obeso é, quase sempre, ser tratado de modo singular em relação à alimentação, ao vestuário, é ser alvo de chacota e apelidos, é ser sexualmente desinteressante, lembrando que na adolescência surgem os primeiros sinais mais representativos da sexualidade humana 28 . O sentimento de inquietação e angústia frente à obesidade impede que os adolescentes reflitam sobre os problemas alimentares e vivenciem com naturalidade as situações comuns a esse período.

Os resultados do trabalho também mostraram a importância da religiosidade no cotidiano do adolescente, no entanto, o tema surgiu apenas no atendimento coletivo. Garcia 7 lembra que os serviços de saúde pouco consideram os aspectos simbólicos inerentes à alimentação, e também descaracterizam qualquer significado que o sujeito tenha atribuído aos alimentos. As religiões configuram uma parte importante da realidade do sujeito e para Chauí 31, a experiência do sagrado pode ser boa ou má, benéfica ou maléfica. Os alimentos podem estar relacionados aos ritos sagrados, conforme referido pelos adolescentes em relação à quaresma, o que reforça a percepção de que os alimentos não estão unicamente restritos à perspectiva técnica da nutrição, mas às diversas situações percebidas e sentidas no cotidiano.

As orientações com vistas apenas à mudança dietética visando a um resultado específico, pouco contribuem para que o adolescente compreenda os determinantes sociais que conformam os padrões de comportamento alimentar. As orientações, quando inadequadas e restritivas, apenas favorecem a formação de barreiras, dificultando a adoção de estilos de vida mais saudáveis 6 .

Propõe-se uma abordagem educativa fundamentada no pensamento pedagógico de Paulo Freire que se identifica com a pedagogia da autonomia 9, a qual enfatiza os aspectos inerentes da realidade de vida do sujeito, o diá- logo entre educador e educando, e a submissão da ciência e da técnica às necessidades tais quais sentidas e percebidas pelos homens.

\section{Conclusão e recomendações}

O método foi efetivo para ajudar os adolescentes a modificar a alimentação. A efetividade na redução de peso foi parcial e dois aspectos devem ser considerados nessa avaliação; primeiro, o fato de que alguns deles traziam na sua história uma carga de experiências negativas procedentes de atendimentos anteriores; segundo, não foram utilizadas técnicas de medição que permitissem avaliar alterações na proporção da massa magra e tecido adiposo. Nessa fase, pode haver mudanças importantes nessa relação ao longo de oito meses, período do estudo, e o índice de massa corporal é um indicador limitado para essa análise.

A problematização é um processo educativo que resgata aspectos particulares da história de vida, bem como os determinantes sociais, políticos e culturais, com o objetivo de fazer com que o sujeito desse processo descubrase singular dentro do coletivo.

A problematização contribuiu para a ampliação da compreensão das práticas próprias ao comportamento alimentar dos adolescentes, possibilitando-lhes reflexão e busca de estratégias para pequenas mudanças no seu cotidiano, modificando assim, seu estilo de vida e a qualidade de sua alimentação.

As orientações recebidas de outras fontes conflitaram com as orientações do programa, contribuindo para a manutenção ou emergência dos problemas. A família é um elemento fundamental no tratamento do adolescente obeso, necessitando também de acolhimento em programas de educação nutricional.

No atendimento coletivo, os adolescentes privilegiaram a problematização de aspectos familiares, afetivos e religiosos, enquanto no atendimento individual houve maior exploração das práticas alimentares. Portanto, as áreas de conhecimento da nutrição, associadas a outras áreas de conhecimento como psicologia e educação física, podem oferecer, por meio de uma abordagem interdisciplinar, um cuidado global ao adolescente obeso, uma vez que o comer contempla igualmente aspectos nutricionais, afetivos, sociais e culturais.

O tratamento do adolescente obeso, no contexto da educação nutricional, requer participação longa para que as etapas do processo de aconselhamento se efetivem, exige consultas freqüentes com intervalos regulares e conheci- 
mento dos profissionais sobre os determinantes sociais que interferem no comportamento alimentar do adolescente.

Para a participação dos adolescentes nesse processo, é conveniente que os profissionais de saúde incentivem os adolescentes ao rompimento de um estado passivo, permitindo-lhes trazer reflexões que transformem a sua realidade marcada pelo estigma e discriminação.

Resumo

Obesidade é um problema de saúde pública em cuja etiologia determinantes sociais têm relevância, sendo que intervenções com adolescentes encontram condição biopsicossocial complexa. A pesquisa avaliou intervenção de educação nutricional, empregando o método da problematização, com 22 adolescentes obesos, atendidos coletiva e individualmente, durante oito meses. Falas foram coletadas mediante emprego de tarjetas, registro por observador e gravação. O método foi qualitativo e a técnica, a análise de conteúdo. A problematização mostrou-se instrumento facilitador para mudança de comportamento alimentar, fazendo emergir reflexões sobre: práticas alimentares, contexto familiar, estigma social, relacionamento com profissionais de saúde, religiosidade. Os adolescentes em atendimento individual problematizaram com mais efetividade práticas alimentares, enquanto no coletivo houve maior problematização dos aspectos familiares e psicológicos, com efetivas mudanças qualitativas na alimentação de ambos os grupos. Concluiu-se que a intervenção foi eficaz para ajudar os adolescentes a compreenderem sua história de vida e determinantes do comportamento alimentar, efetivarem mudanças na sua alimentação espontaneamente, conscientizarem-se das possibilidades de perpetuação da mudança das práticas alimentares e exercerem com autonomia o papel de sujeitos no cuidado à saúde.

Educação Nutricional; Educação em Saúde; Obesidade; Nutrição do Adolescente
A educação nutricional deve agregar os conhecimentos do campo da antropologia da alimentação e os fundamentos teóricos do campo da educação, para que esteja inserida em um contexto político-social de promoção à saúde e qualidade de vida.

\section{Colaboradores}

E. M. Rodrigues foi responsável pela revisão da literatura, realizou a coleta e análise de dados e redigiu o artigo. M. C. F. Boog contribuiu na análise dos dados e na redação do artigo para publicação. 


\section{Referências}

1. Instituto Brasileiro de Geografia e Estatística. Pesquisa de orçamentos familiares 2002-2003: análise da disponibilidade domiciliar de alimentos e do estado nutricional no Brasil. Rio de Janeiro: Instituto Brasileiro de Geografia e Estatística; 2004.

2. Magalhães VC, Mendonça GAS. Prevalência e fatores associados a sobrepeso e obesidade em adolescentes de 15 a 19 anos das regiões Nordeste e Sudeste do Brasil, 1996 a 1997. Cad Saúde Pública 2003; 19 Suppl 1:S129-39.

3. Boog MCF. Educação nutricional em serviços públicos de saúde: busca de espaço para ação efetiva [Tese de Doutorado]. São Paulo: Universidade de São Paulo; 1996.

4. Müller RCL. A história familiar e a obesidade na adolescência: um estudo clínico-qualitativo com adolescentes obesos [Tese de Doutorado]. Campinas: Universidade Estadual de Campinas; 1999.

5. Holli BB, Calabrese RJ. Communication and education skills: the dietitian's guide. Philadelphia: Lea \& Febiger; 1986.

6. Motta DG. Subsídios para educação em diabetes: representações de mulheres sobre sua doença e tratamento. Saúde em Revista 2001; 3:7-14.

7. Garcia RWD. A comida, a dieta, o gosto: mudanças na cultura alimentar urbana [Tese de Doutorado]. São Paulo: Universidade de São Paulo; 1999.

8. Fischler C. El (h)omnívoro: el gusto, la cocina, y el cuerpo. Barcelona: Anagrama; 1995.

9. Freire P. Pedagogia da autonomia: saberes necessários à prática educativa. São Paulo: Paz e Terra; 2000.

10. Rodrigues EM, Soares, FPTP, Boog MCF. Resgate do conceito de aconselhamento no contexto do atendimento nutricional. Rev Nutr 2005; 18:11928.

11. Hackey H, Nye S. Aconselhamento: estratégias e objetivos. São Paulo: EPU; 1977.

12. Minayo MCS. O desafio do conhecimento: pesquisa qualitativa em saúde. São Paulo: Editora Hucitec/Rio de Janeiro: ABRASCO; 1996.

13. Mizukami MGN. Ensino: as abordagens do processo. São Paulo: EPU; 1986.

14. Rodrigues, EM. Problematização do comportamento alimentar como estratégia de educação nutricional: uma experiência com adolescentes obesos [Dissertação de Mestrado]. Campinas: Universidade Estadual de Campinas; 2003.

15. Triviños ANS. Introdução à pesquisa em ciências sociais: a pesquisa qualitativa em educação. São Paulo: Atlas; 1987.
16. Pizzinato VT. Obesidade infantil: processo psicossomático evolutivo. São Paulo: Sarvier; 1992.

17. Nóbrega FJ, Campos ALR. Distúrbios nutricionais e fraco vínculo mãe/filho. Rio de Janeiro: Revinter; 1996.

18. Lattimore PJ, Butterworth M. A test of the structural model of initiation of dieting among adolescent girls. J Psychosom Res 1999; 46:295-9.

19. Buss PM. Promoção da saúde e qualidade de vida. Ciênc Saúde Coletiva 2000; 5:163-77.

20. Formigli VLA, Costa COM, Porto LA. Avaliação de um serviço de atenção integral à saúde do adolescente. Cad Saúde Pública 2000; 16:831-41.

21. Morin E. Os sete saberes necessários à educação do futuro. São Paulo: Cortez; 2001.

22. Sawaya AL, Ferrari AA, Ugnebo CH, Solymos GMB, Vieira MFA, Souza MHN. Desnutrição urbana no Brasil: um período de transição. São Paulo: Cortez; 1997.

23. Sichieri R. Epidemiologia da obesidade. Rio de Janeiro: EdUERJ; 1998.

24. Doak CM, Adair LS, Monteiro CA, Popkin BM. Overweight and underweight coexist within households in Brazil, China and Russia. J Nutr 2000; 130:2965-71.

25. Hanley AJG, Harris SB, Gittelsohn J, Wolever TMS, Saksvig B, Zinman B. Overweight among children and adolescents in a Native Canadian community: prevalence and associated factors. Am J Clin Nutr 2000; 71:693-700.

26. Onis M, Blössner M. Prevalence and trends of overweight among preschool children in developing countries. Am J Clin Nutr 2000; 72:1032-9.

27. Gama CM. Consumo alimentar e estado nutricional de adolescentes matriculados em escolas da rede particular e estadual do bairro de Vila Mariana, São Paulo [Tese de Doutorado]. São Paulo: Universidade Federal de São Paulo; 1999.

28. Gikovate F. Deixar de ser gordo. São Paulo: MG Editores Associados; 1986.

29. Bruss MB, Morris J, Dannison L. Prevention of childhood obesity: sociocultural and familial factors. J Am Diet Assoc 2003; 103:1042-5.

30. Tonial SR. Desnutrição e obesidade: faces contraditórias na miséria e na abundância. Recife: Instituto Materno Infantil de Pernambuco; 2001.

31. Chauí M. Convite à filosofia. São Paulo: Ática; 1995.

Recebido em 19/Ago/2004

Versão final reapresentada em 01/Jul/2005

Aprovado em 02/Set/2005 